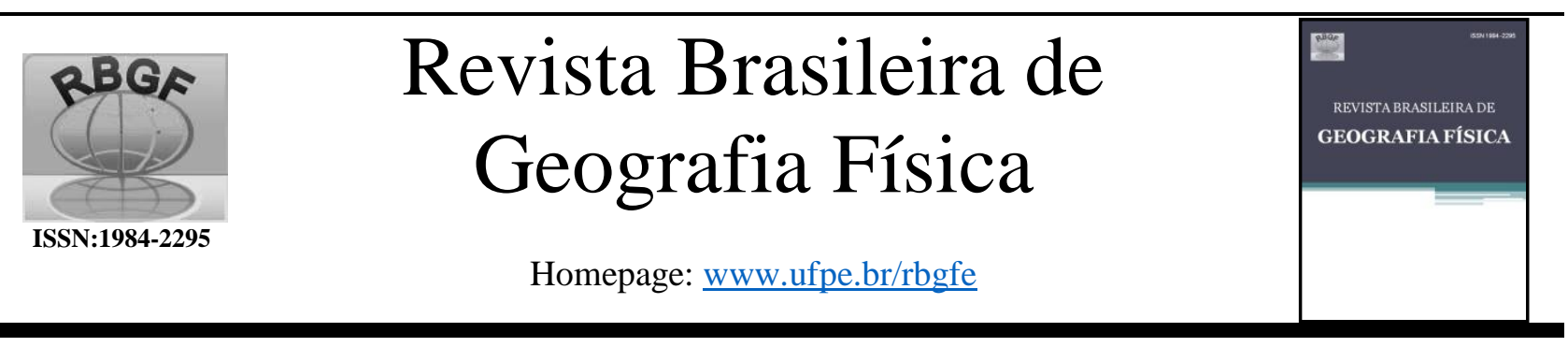

\title{
Classificação do estado de Goiás e do Distrito Federal segundo o sistema de zonas de vida de holdridge
}

\author{
Alexandre Dal Forno Mastella ${ }^{1}$, Severo Ivasko Júnior ${ }^{1}$, Andressa Tres ${ }^{1}$, Alexandre França Tetto², \\ William Thomaz Wendling 2 , Ronaldo Viana Soares ${ }^{2}$.
}

${ }^{1}$ Doutorando (a) do Programa de Pós-Graduação em Engenharia Florestal da Universidade Federal do Paraná (PPGEF/ UFPR), Curitiba, PR - Brasil. Autor para correspondência, e-mail: alexandremastella@gmail.com; severoivasko@gmail.com; tres.andressa@gmail.com; ${ }^{2}$ Professor Doutor do Programa de Pós-Graduação em Engenharia Florestal da Universidade Federal do Paraná (PPGEF/UFPR), Curitiba, PR - Brasil, e-mail: tetto@ufpr.br; wendling@ufpr.br; rvsoares@ufpr.br.

Artigo recebido em 26/11/2018 e aceito em 24/02/2019

\begin{abstract}
R E S U M O
É imprescindível que se tenha conhecimento das condições climáticas de uma região para execução de diversas atividades. Entre as classificações climáticas mais conhecidas, a de Köppen é a mais usual. Porém, Leslie R. Holdridge elaborou um sistema de classificação no qual são determinadas zonas de vida, as quais representam associações ecológicas semelhantes. O objetivo da presente pesquisa foi classificar o clima dos municípios de Goiás e o Distrito Federal segundo Holdridge, comparando-os com o mapa de vegetação do referido estado elaborado pelo IBGE e com o mapa da classificação climática de Köppen. Mediante uma base de dados elaborada por Alvares et al. (2013), foram extrapolados valores de precipitação e temperatura para os 246 municípios de Goiás e o Distrito Federal. Aliado ao cálculo da biotemperatura e relação de evapotranspiração potencial, juntamente com o estabelecimento da região latitudinal e piso altitudinal local, foram determinadas as zonas de vida. Os resultados mostraram duas zonas de vida para a área de estudo: floresta úmida tropical premontana (99,4\% do território), correlacionada 96,88\% com o clima Aw; e floresta seca/floresta úmida tropical basal, correlacionada $100 \%$ com o clima Aw. A biotemperatura foi a variável que diferiu para dois municípios localizados no extremo norte do estado, possibilitando o surgimento da zona de vida floresta seca/floresta úmida tropical basal, que correspondeu a $0,6 \%$ do território. O emprego do sistema de classificação climática de Holdridge foi adequado para classificar o clima de Goiás e do Distrito Federal pois correspondeu com a classificação de Köppen e com a vegetação. Palavras-chave: climatologia, biotemperatura, cerrado, vegetação.
\end{abstract}

\section{Classification of Goiás State and the Federal District according to the Holdridge Life Zones System}

\begin{abstract}
A B S T R A C T
It is essential to have knowledge of the climatic conditions of a region to carry out various activities. Among the bestknown climatic classifications, Köppen's climate classification is the most usual. However, Leslie R. Holdridge has developed a classification system in which are determined the life zones, which represent similar ecological associations. The aim of this research was to classify the climate of the municipalities of Goiás and the Federal District according to Holdridge, comparing them with the vegetation map of the state prepared by the IBGE and with the climate classification map of Köppen. Using a database developed by Alvares et al. (2013), precipitation and temperature values were extrapolated to the 246 municipalities of Goiás and the Federal District. Ally with the calculation of biotemperature and relation of potential evapotranspiration, jointly with the establishment of the latitudinal region and local altitudinal levels, the life zones were determined. The results showed two life zones for the study area: tropical premontane moist forest (99.4\% of the territory) correlated $96.88 \%$ with the Aw climate; and tropical dry forest/moist forest correlated $100 \%$ with the Aw climate. Biotemperature was the variable that differed for two municipalities located in the extreme north of the state, which allowed the appearing of the tropical dry forest/moist forest life zone that corresponded to $0.6 \%$ of the territory. The use of the Holdridge climate classification system was adequate to classify the Goiás and the Federal District climate because it corresponded to the classification of Köppen and to the vegetation.
\end{abstract}

Key-words: climatology, biotemperature, cerrado, vegetation. 


\section{Introdução}

O estudo do tempo e do clima ocupa uma posição central e importante no amplo campo da ciência ambiental (Ayoade, 2010), sendo imprescindível que se tenha conhecimento das condições climáticas de uma região para a execução de um projeto de recuperação, por exemplo; relacionando as particularidades do clima local com as características da vegetação a ser introduzida, visando a otimização das tarefas. Da mesma forma, tanto na agropecuária quanto no setor de florestas plantadas com finalidade comercial, é necessária a compreensão da classificação climática para que se possa planejar o empreendimento de forma segura, ou seja, conforme Nascimento et al. (2015), o entendimento da variabilidade dos elementos climáticos de determinada localidade torna-se importante para o subsídio do planejamento urbano, rural, regional e ambiental. Com isso, se viabiliza a constituição de zoneamentos ecológicos para a gestão dos ecossistemas, da biodiversidade e do uso da terra (Derguy, 2017).

De acordo com Tres (2016), o clima e a vegetação possuem uma estreita relação, onde ambos são mutualmente influenciáveis, pois, localmente, a introdução da vegetação pode modificar o clima de um bairro ou município, já, em uma escala maior, o clima e suas variações podem ocasionar o deslocamento de espécies e a mudança de ecossistemas. Além disso, Alencar et al. (2014) afirmam que, atualmente, deve-se compreender como as alterações dos elementos climáticos estão modificando o clima de uma área. Assim, o entendimento da classificação climática de uma região torna-se fundamental para a introdução de novas culturas, aumento da produtividade daquelas existentes e melhoria da qualidade dos produtos gerados (Soares et al., 2015).

O clima de um local pode ser classificado de diferentes formas. Segundo Ayoade (2010), as classificações climáticas visam, entre outros objetivos, fornecer uma estrutura para organizar os dados do clima a fim de simplificar, esclarecer e compreender os complexos padrões climáticos do mundo. Entre as classificações mais conhecidas, o sistema de classificação proposto por Köppen é o mais usual, sendo empregado cotidianamente. Para Dias Cardoso et al. (2014), neste modelo, os elementos de temperatura e precipitação constituem um critério inicial para a divisão dos tipos de clima. De acordo com Alvares et al. (2013), a classificação de Köppen não se limita ao ensino, pois, em toda a sua história, muitos pesquisadores a utilizaram rotineiramente em seus projetos de pesquisa. Tal classificação é considerada ainda hoje satisfatória para uma discussão geral sobre o clima da Terra, porém não atende áreas específicas como a silvicultura, agronomia, ecologia, entre outras (Eloi, 2001).

Conforme Torres e Machado (2008), Leslie Ransselaer Holdridge propôs em 1947 uma classificação bioclimática que relaciona a distribuição dos ecossistemas com a biotemperatura média anual, a precipitação média anual e a evapotranspiração potencial (ETP). De acordo com Soares et al. (2015), trata-se de um engenhoso sistema de classificação denominado de zonas de vida e baseado em parâmetros que afetam sensivelmente a vegetação. Os autores destacam que ao comparar a classificação de Köppen com Holdridge, de forma geral o sistema de Köppen caracteriza-se por ser mais geográfico e o de Holdridge mais ecológico, uma vez que conceitua biotemperatura como uma medida de energia, naquela porção efetiva onde há real crescimento da vegetação, compreendida pelo intervalo de temperatura de 0 a $30{ }^{\circ} \mathrm{C}$.

De acordo com Tres (2016), a classificação climática de Holdridge é alicerçada em parâmetros climáticos, biotemperatura e precipitação; e nãoclimáticos, latitude e altitude, com o objetivo de agrupar associações ecológicas semelhantes em um nível superior. Neste aspecto, criam-se condições de se caracterizar o clima de um local por meio de critérios que valorizem a adaptação de espécies vegetais a um nicho ecológico, onde as plantas são equivalentes quanto a sua fisionomia, mesmo que classificadas distintas taxonomicamente (Holdridge, 2000). Tais fatores proporcionam uma classificação alternativa e eficiente para caracterizar o clima e a vegetação de países tropicais, como é o caso do Brasil.

Devido à importância econômica e ambiental que o estado de Goiás ostenta para o país, é oportuno que seja realizada uma adequação climática com base em tais aspectos.

Goiás tem quase todo o seu território inserido no bioma cerrado, exceto 3,5\% de sua área total, localizada no sudeste do estado, que está dentro do domínio do bioma Mata Atlântica (Dias Cardoso et al., 2014). Conforme Oliveira (2014), o cerrado tem, em sua fisionomia, variações que vão de formas florestadas (matas secas, de galeria ou ciliares) até formações tipicamente campestres (campos sujos, limpos ou rupestres) cujos limites nem sempre são bem definidos. Conforme o autor, originalmente a área compreendida pelo domínio do cerrado cobria cerca de $1 / 4$ do território brasileiro, hoje, a maior parte das terras foi incorporada por atividades econômicas 
(agricultura e pecuária), sendo que os remanescentes da vegetação original - fragmentos pequenos e dispersos - tornaram-se incapazes de conservar a biodiversidade natural.

Pela intrínseca relação existente entre o clima e o desenvolvimento da vegetação, o objetivo da presente pesquisa foi classificar o clima dos municípios de Goiás e o Distrito Federal segundo o sistema de zonas de vida proposto por Holdridge, comparando-os com o mapa de vegetação do referido estado elaborado pelo Instituto Brasileiro de Geografia e Estatística (IBGE, 2012) e com o mapa da classificação climática de Köppen confeccionado por Alvares et al. (2013).

\section{Material e métodos}

\section{Caracterização da área de estudo}

O estado de Goiás possui uma área de $340.111,78 \mathrm{~km}^{2}$ (Instituto Mauro Borges de Estatísticas e Estudos Sócio-econômicos (IMB, 2014) que, somada a área correspondente ao Distrito Federal 5.779,00 $\mathrm{km}^{2}$ (Governo de Brasília, 2018) perfaz um total de $345.890,78 \mathrm{~km}^{2}$. Localizado na região centro-oeste do Brasil e delimitado pelas coordenadas geográficas $12^{\circ} 23^{\prime}$ $41^{\prime \prime}$ e $19^{\circ} 29^{\prime} 55^{\prime \prime}$ de latitude sul e $45^{\circ} 54^{\prime} 21^{\prime \prime}$ e $53^{\circ} 15^{\prime}$ 06" de longitude oeste (Nascimento et al., 2015), limita-se ao norte com o estado do Tocantins, ao sul com Minas Gerais e Mato Grosso do Sul, a leste com a Bahia e Minas Gerais e a oeste com Mato Grosso (IMB, 2014). Segundo o mesmo autor, via de regra, o solo de Goiás é classificado como latossolo e quanto à hidrografia, o estado possui rios que alimentam três importantes regiões hidrográficas do país (Araguaia/Tocantins, São Francisco e Paraná), formando uma rede de drenagem densa, sendo a unidade da federação que possui o maior número de províncias hidrogeológicas - um potencial hídrico bastante aproveitado sobretudo com a utilização de pivôs centrais de irrigação na agricultura. De acordo com Toledo e Moraes (2018), entre os sistemas de irrigação, o uso de pivô central foi o que mais cresceu no país nos últimos anos, principalmente no estado de Goiás. Para Penereiro et al. (2015), a região da bacia hidrográfica do TocantinsAraguaia é considerada, hidrologicamente, a maior bacia estabelecida inteiramente em território brasileiro com um elevado potencial hidroenergético.

Com base na classificação climática de Köppen, Alvares et al. (2013) definiram o clima de Goiás e do Distrito Federal como sendo do tipo Aw (clima tropical com inverno seco), com exceção de uma pequena porção localizada ao sul, na divisa com Mato Grosso do Sul, classificada como do tipo Am (clima tropical de monção). Os mesmos autores definiram médias de temperatura anuais para o estado variando de 20 a $26^{\circ} \mathrm{C}$ e índices pluviométricos anuais de $1.300-1.900 \mathrm{~mm}$ (Figura 1). 


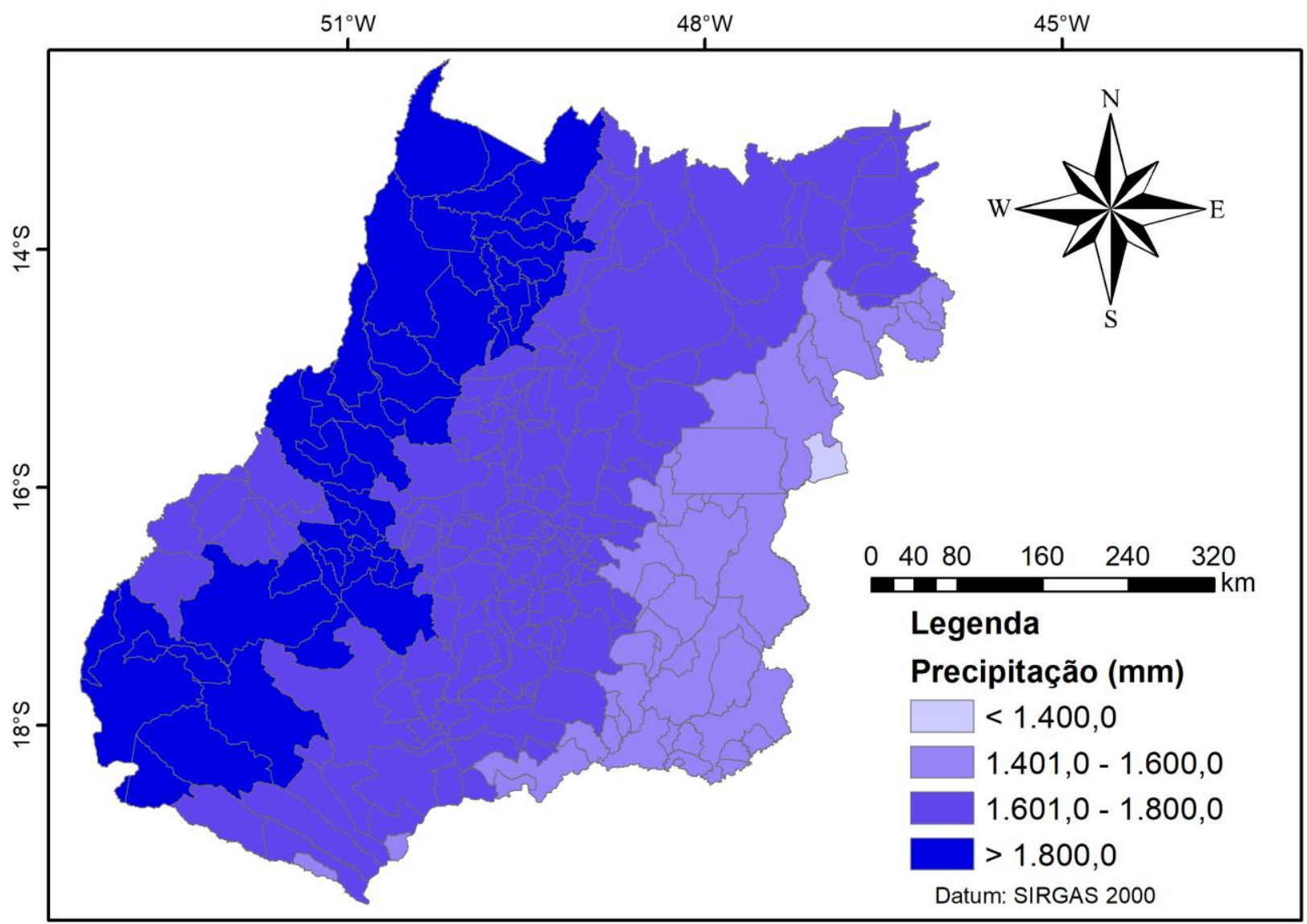

Figura 1. Médias de precipitação anual para o estado de Goiás e o Distrito Federal. Fonte: Alvares et al. (2013), elaborado pelos autores (2018).

Segundo Oliveira (2014), como os componentes do clima são interligados, isso significa que alterações na temperatura do ar também provocam mudanças nos demais índices, como a pressão atmosférica, a umidade e até mesmo a circulação das massas de ar. Com isso, para o autor, tais oscilações relacionam-se com as mudanças no perfil altimétrico do relevo, que, na área de estudo, se caracteriza por apresentar extensas áreas planas ou suavemente onduladas, dominando as paisagens em quase todas as regiões com variações altimétricas inferiores a $200 \mathrm{~m}$ até pouco mais de $1.600 \mathrm{~m}$ (Figura 2). 


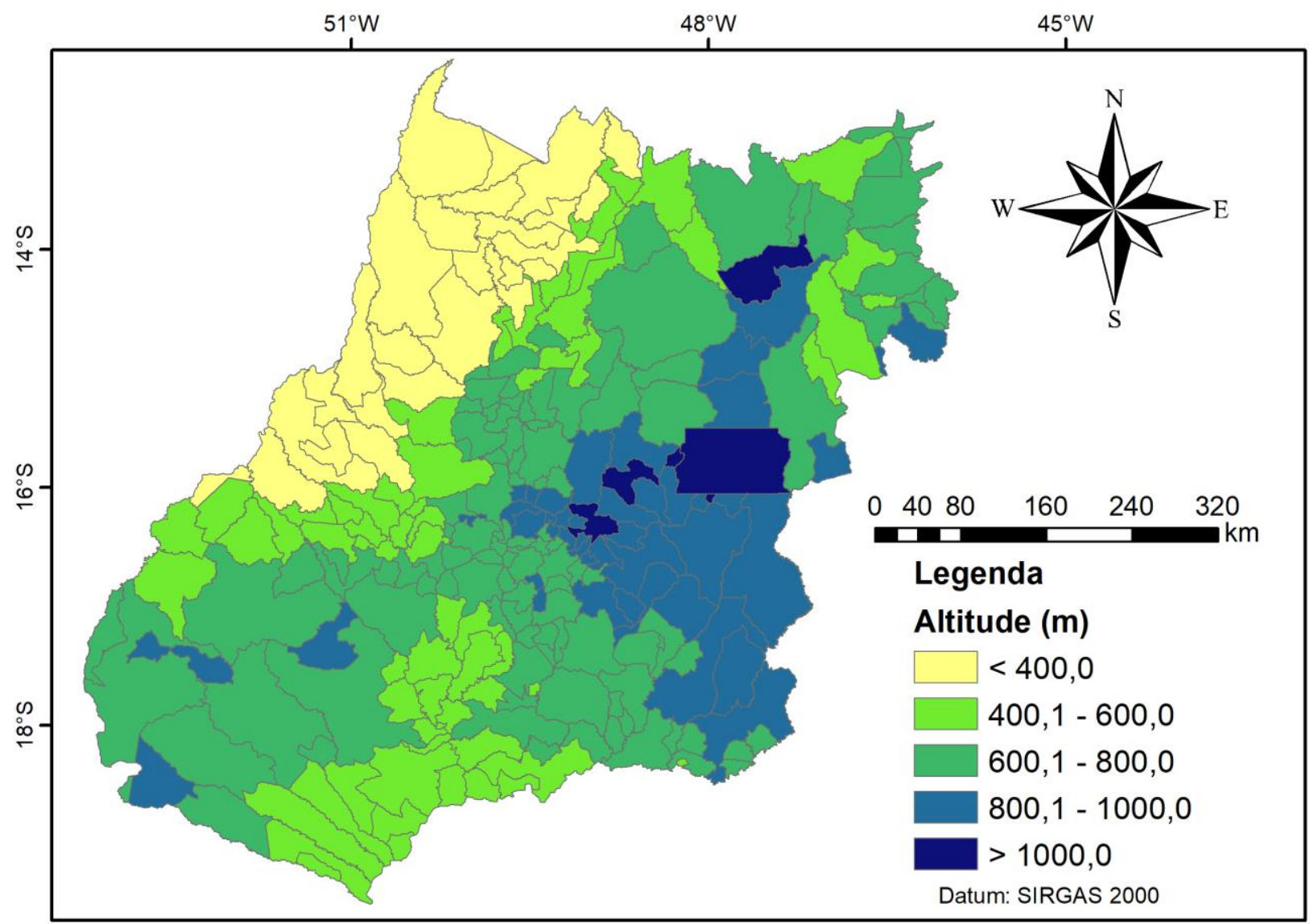

Figura 2. Médias de altitude para o estado de Goiás e o Distrito Federal. Fonte: Alvares et al. (2013), elaborado pelos autores (2018).

De acordo com o IBGE (2018a; 2018b), a população estimada dos 246 municípios goianos somada à do Distrito Federal corresponde a 9.895.864 pessoas. A economia, voltada principalmente para agricultura - lavouras de soja - e pecuária, possui algumas peculiaridades. Abdala e Ribeiro (2011) detalham que a cultura da cana-de-açúcar está substituindo áreas com culturas tradicionais como milho, algodão, arroz, feijão, entre outras, paralelo ao aumento do rebanho bovino, confirmando a importância da agropecuária e da cana-de-açúcar na geração de divisas para a região. Concomitantemente, é significativa a pressão exercida sobre a vegetação nativa - remanescentes do bioma cerrado. Segundo Marinho et al. (2016), na região centro-oeste, o intenso crescimento econômico e demográfico das últimas décadas compromete a conservação dos recursos hídricos e florestais.

O IBGE (2012) conceitua cerrado como uma vegetação xeromorfa que ocorre sob distintos tipos de clima, revestindo solos lixiviados e aluminizados. Com base em tal classificação, Oliveira (2014) faz uma correlação entre as denominações típicas do cerrado: a savana arbórea densa equivale ao cerradão; a savana arbórea é equivalente ao cerrado "stricto sensu" e ao campo cerrado; a savana parque é o campo sujo de cerrado e a savana gramíneo-lenhosa equivale ao campo limpo de cerrado. De acordo com Rigonato e Almeida (2003), a porção norte da região ainda detém parcialmente preservada a fisionomia savana arbórea densa no Parque Nacional da Chapada dos Veadeiros, município de Alto Paraíso, em relação à outras porções da área de estudo.

\section{Coleta de dados}

Os dados climáticos foram obtidos por meio do banco de dados disponibilizado por Alvares et al. (2013). Os dados foram extrapolados para os 246 municípios do estado mais o Distrito Federal. De acordo com estes dados, as temperaturas médias mensais variaram de $20,3{ }^{\circ} \mathrm{C}$ no mês de julho a $24,6{ }^{\circ} \mathrm{C}$ no mês de outubro. A Figura 3 apresenta uma relação entre as médias mensais de temperatura e precipitação para o estado de Goiás e o Distrito Federal. 


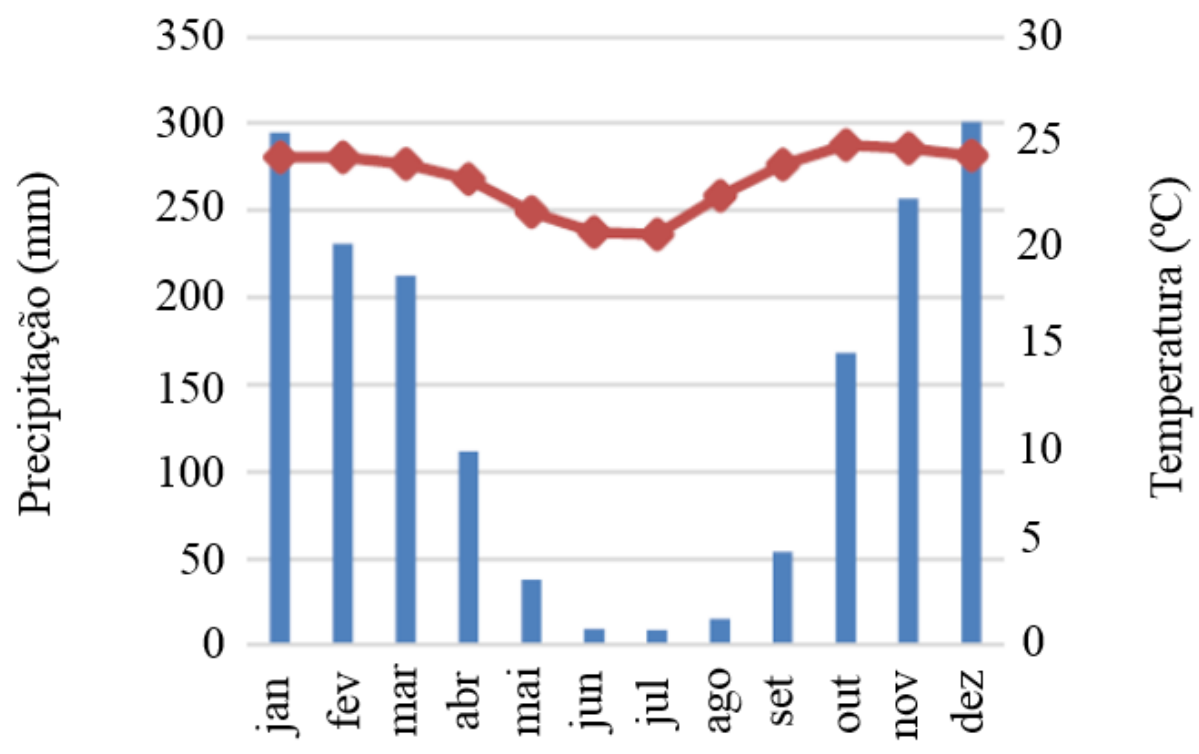

Meses do ano

Precipitação $(\mathrm{mm}) \sim$ Temperatura $\left({ }^{\circ} \mathrm{C}\right)$

Figura 3. Médias mensais de temperatura e precipitação para o estado de Goiás e o Distrito Federal. Fonte: Alvares et al. (2013), elaborado pelos autores (2018).

Como se pode observar, a menor média mensal de precipitação foi encontrada no mês de julho $(8,7 \mathrm{~mm})$ e a maior no mês de dezembro $(300,8 \mathrm{~mm})$. Alves (2016) afirma que há grande variabilidade no regime pluviométrico local, pois, em um estudo buscando verificar a existência de tendência nas séries temporais de precipitação para a área, o autor encontrou uma média de $1.515 \mathrm{~mm}$ com variação de 1.130 a $2.040 \mathrm{~mm}$. Uma vez que a distribuição da precipitação durante o ano é um fator decisivo para caracterização do clima de uma região, bem como para a irrigação de culturas e o abastecimento de água doméstico e industrial, além de ser um fator preponderante para o planejamento das atividades agrícolas (Almeida et al., 2018), graças aos acumulados de precipitação e potencial para irrigação no período seco, a região pode figurar entre as grandes produtoras de grãos do país.

\section{Classificação de Holdridge}

A classificação de Holdridge foi efetuada seguindo a metodologia proposta por Holdridge (2000), onde é considerado o cálculo da biotemperatura, precipitação e a relação de evapotranspiração potencial (ETP) para determinar as zonas de vida do referido sistema. A classificação é finalizada com a definição da região latitudinal e do piso altitudinal do local.

\section{Análise dos dados}

Para verificar a afinidade do sistema de classificação de Holdridge com outras metodologias de classificação climática e com a vegetação, o mesmo foi comparado com a classificação climática de Köppen (Figura 4) e com o mapa de vegetação (Figura 5). 


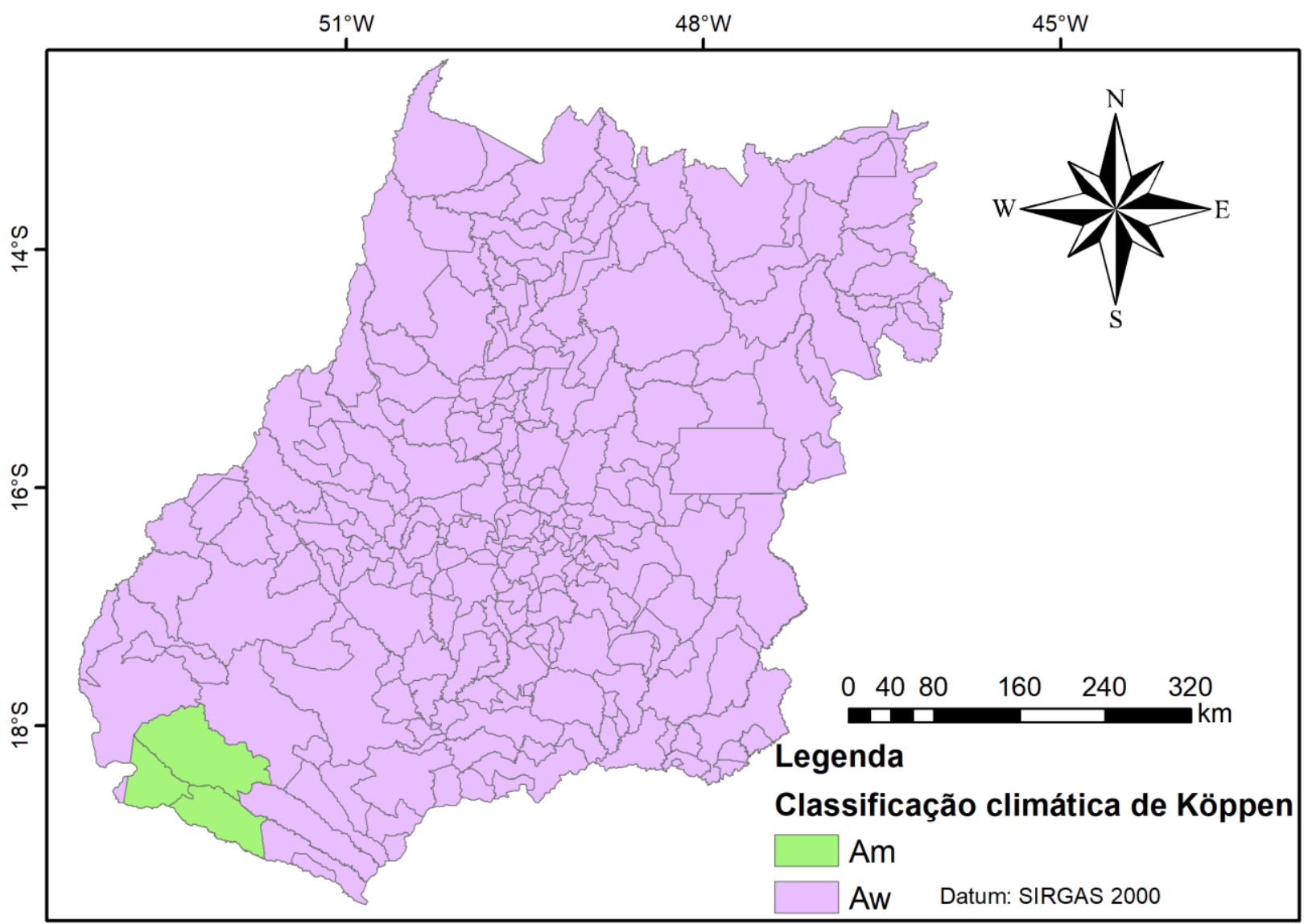

Figura 4. Classificação climática de Köppen para o estado de Goiás e o Distrito Federal. Fonte: Alvares et al. (2013), elaborado pelos autores (2018).

Observa-se que a área está dividida em duas classificações climáticas de Köppen: clima do tipo Aw (clima tropical com inverno seco) e clima do tipo Am (clima tropical de monção).

De acordo com a Embrapa (2018), o clima do tipo Aw apresenta estação chuvosa no verão, de novembro a abril, com precipitação anual superior a $750 \mathrm{~mm}$ podendo atingir $1.800 \mathrm{~mm}$, sendo nítida a ocorrência de estação seca no inverno, de maio a outubro, tendo o mês de julho como o mais seco. De acordo com Soares et al. (2015), a precipitação neste período é inferior a $60 \mathrm{~mm}$ e a temperatura média superior a $18{ }^{\circ} \mathrm{C}$. Já o clima do tipo Am apresenta uma estação seca de pequena duração, compensada pelos totais elevados de precipitação (EMBRAPA, 2018), que, segundo Soares et al. (2015), são maiores que $2.500 \mathrm{~mm}$ anuais aliados a uma temperatura média do mês mais frio superior a $18^{\circ} \mathrm{C}$.

Segundo Dias Cardoso et al. (2014), na região centro-oeste, o tempo seco no inverno tem sua origem na estabilidade gerada pela influência do anticiclone subtropical do Atlântico Sul e de pequenas dorsais que se formam sobre a parte continental sul americana, enquanto que, o período de chuva, está associado ao deslocamento para o sul da Zona de Convergência Intertropical (ZCI, também conhecida como CIT), acompanhando a marcha aparente do sol em direção ao Trópico de Capricórnio, com isso, sobre a porção central da América do Sul a CIT avança mais para sul do que nas regiões costeiras, gerando instabilidade em todo o Brasil central nos meses de verão. Os autores mencionam ainda que em função da influência da massa de ar tropical marítima e equatorial, as temperaturas na região são elevadas durante todo o ano e, no inverno, quando a CIT está deslocada para norte, a região apresenta baixa ou nenhuma precipitação. 


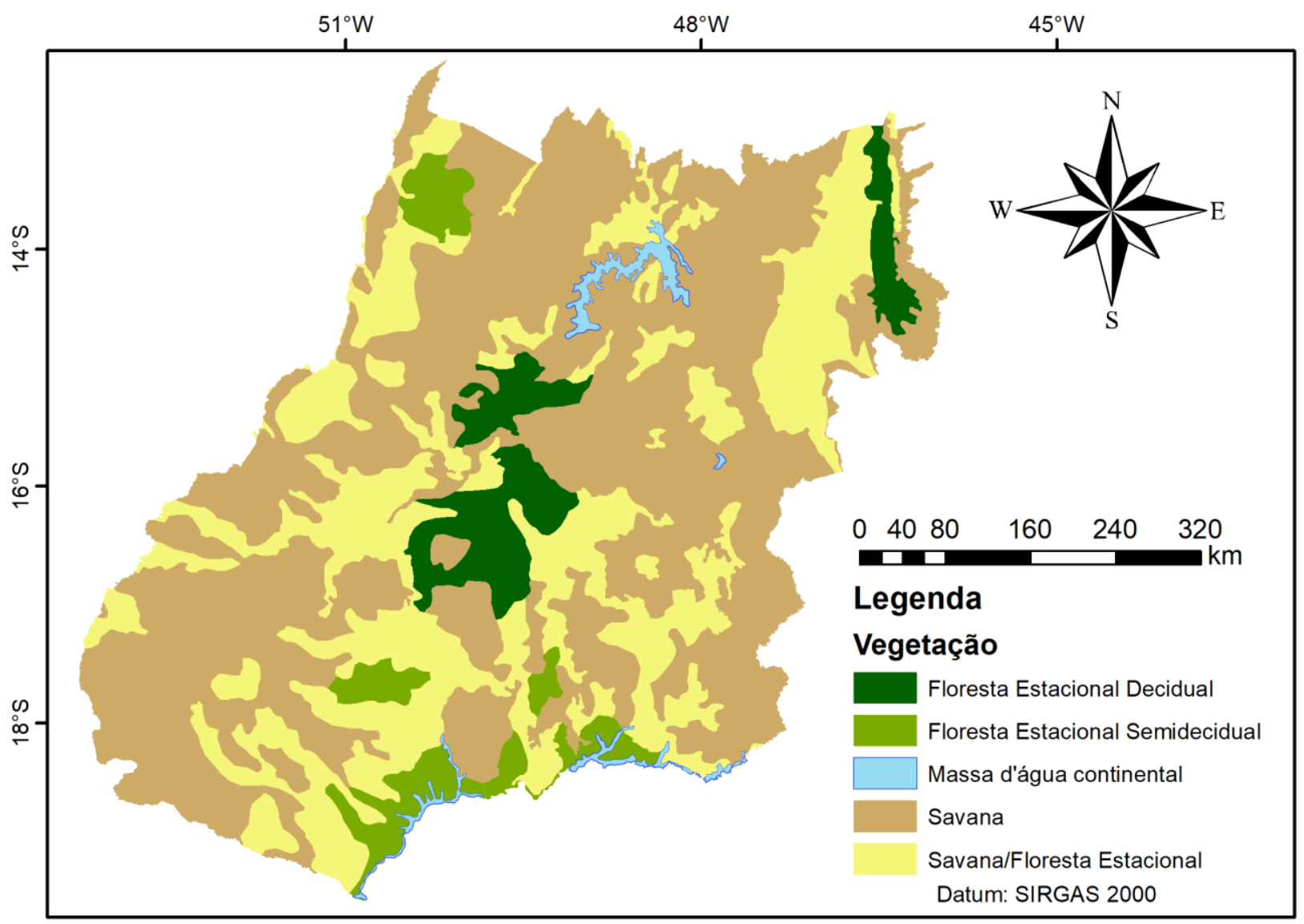

Figura 5. Mapa de vegetação do estado de Goiás e o Distrito Federal. Fonte: IBGE (2012), elaborado pelos autores (2018).

A maior parte da vegetação é classificada como savana - vegetação típica do bioma cerrado - e savana/floresta estacional. Tal classificação é característica do clima Aw (clima tropical com inverno seco) para quase a totalidade da área de estudo. Há ainda a ocorrência de áreas classificadas como floresta estacional semidecidual, na região de transição entre o cerrado e o bioma mata atlântica, divisa com o estado de Minas Gerais, além da floresta estacional decidual ocupando áreas descontínuas do território.
Após determinar em porcentagem a cobertura de cada zona de vida, foi calculada a área de sobreposição entre as mesmas e a classificação climática de Köppen e Holdridge para fins de comparação por meio da ferramenta Zonal Histogram do software ArcGIS.

\section{Resultados e discussão}

\section{Biotemperatura}

A Figura 6 apresenta os valores de biotemperatura $\left({ }^{\circ} \mathrm{C}\right)$ para o estado de Goiás e o Distrito Federal. 


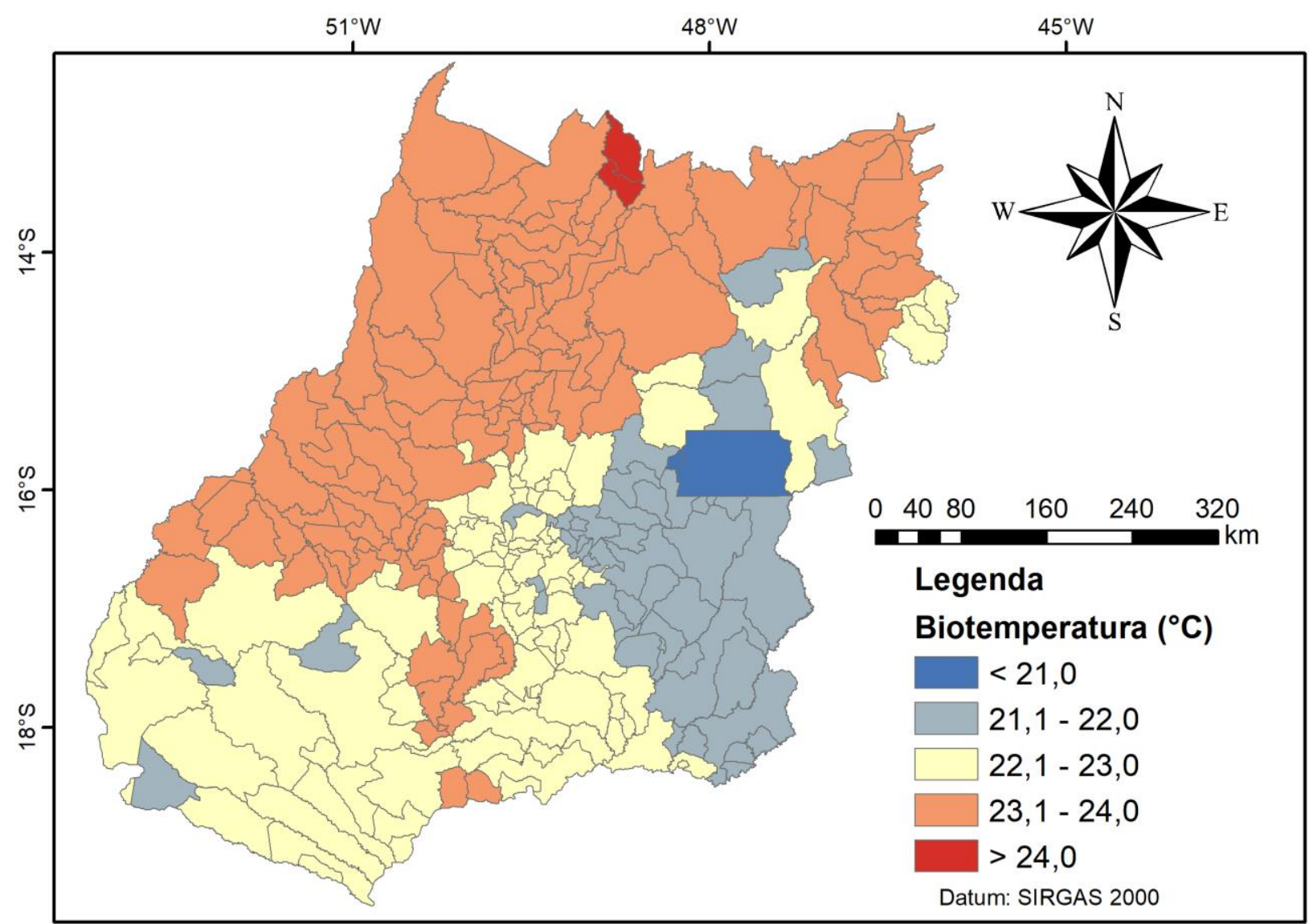

Figura 6. Mapa de biotemperatura do estado de Goiás e o Distrito Federal. Fonte: elaborado pelos autores (2018).

Nota-se pela Figura 6 que existe uma pequena região no extremo norte do estado que apresenta os maiores valores de biotemperatura, valores estes superiores a $24,0^{\circ} \mathrm{C}$. Trata-se de uma área que possui características climáticas mais semelhantes com as das regiões norte e nordeste do país do que com o restante do estado, favorecendo o desenvolvimento de uma vegetação adaptada a um clima seco com altas temperaturas.

Segundo Dias Cardoso et al. (2012), percebe-se que a região mais quente do estado de Goiás é a noroeste, enquanto as temperaturas mais amenas ocorrem em uma região localizada entre os municípios de Goiânia e Anápolis e nas imediações do Distrito Federal, em direção ao sudeste do estado.

Áreas com maior elevação possuem temperaturas mais baixas que aquelas mais próximas ao nível médio do mar (Reboita et al., 2015). É evidente, portanto, que os maiores valores de biotemperatura estão associados às menores altitudes. Na porção oeste do estado, região do rio Araguaia, as cotas de altitude são inferiores a 400 $m$ e a biotemperatura enquadra-se em uma faixa de 23,1 a $24^{\circ} \mathrm{C}$. De acordo com Oliveira (2014), na porção oeste-noroeste de Goiás, em direção ao Vale do Araguaia, a paisagem assemelha-se a uma escadaria em declive a partir da Serra do Caiapó para os níveis mais baixos e extremamente planos da Depressão do Araguaia, com altitudes menores que $300 \mathrm{~m}$ a cerca de $400 \mathrm{~m}$, onde, seguindo o curso do rio, chega-se às a altitudes inferiores a $200 \mathrm{~m}$.

De acordo com Dias Cardoso et al. (2012), é possível dividir a distribuição da temperatura na região em duas zonas, oeste e leste: a zona oeste apresenta a temperatura relacionada com a latitude, onde os valores tendem a ser maiores em latitudes baixas e menores em latitudes altas, tendo um aumento gradual da temperatura de sudoeste a noroeste; entretanto, na região leste, a temperatura sofre influência direta das altitudes mais elevadas que se apresentam de sudeste a nordeste. Nesse contexto, vê-se que os valores de biotemperatura aumentam gradativamente no sentido sul-norte da região associados principalmente à latitude e ao relevo, determinando consequentemente o caráter xeromórfico da vegetação.

\section{Classificação de Holdridge}

Segundo o sistema de classificação proposto por Holdridge, o estado de Goiás e o Distrito Federal apresentam duas zonas de vida como se pode verificar na Figura 7. 


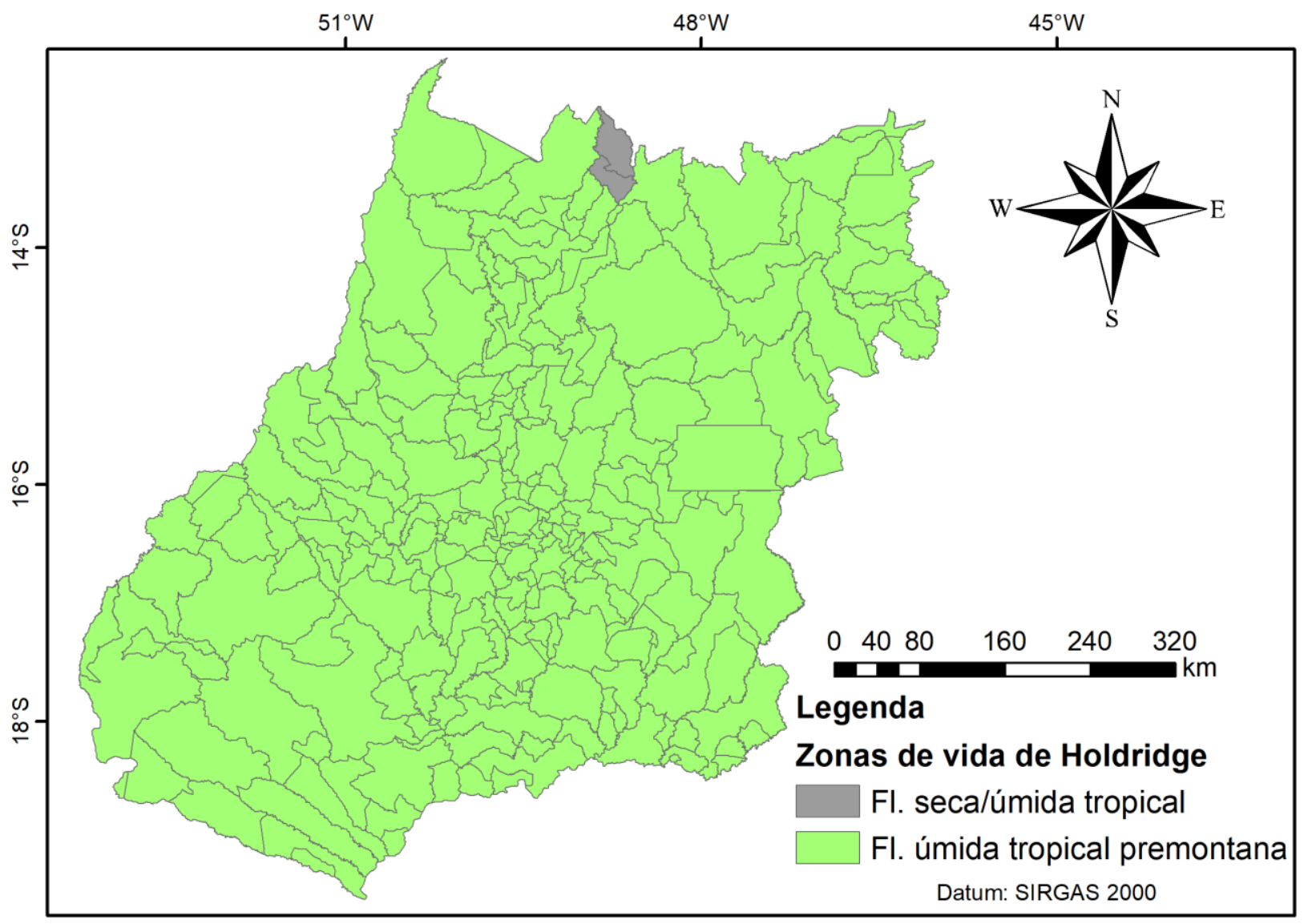

Figura 7. Classificação de Holdridge para o estado de Goiás e o Distrito Federal. Fonte: elaborado pelos autores (2018).

A zona de vida floresta úmida tropical premontana abrange uma área de $343.811,20 \mathrm{~km}^{2}$ equivalente a $99,4 \%$ da área de estudo. A zona de vida floresta seca/floresta úmida tropical basal no entanto, apresenta uma área de $2.075,30 \mathrm{~km}^{2}$ equivalente a $0,6 \%$ do território, sendo constituída por dois municípios localizados no extremo norte: Montividiu do Norte e Trombas. Montividiu do Norte possui altitude inferior a 400 m (389 m), já em Trombas a altitude varia de 400,1 a 600 m (413 $\mathrm{m})$. Apesar da pequena diferença, esta foi a única variável que distinguiu os dois municípios. Ambos apresentam as mesmas classificações quanto ao clima (Aw), precipitação (de 1.601,0 a $1.800,0$ $\mathrm{mm})$, solos - enquadrados como latossolo conforme IMB (2014) - e biotemperatura (> 24,0 ${ }^{\circ} \mathrm{C}$ ), esta última correspondendo a classe em que são encontrados os maiores valores na região. Tais apontamentos indicam que a principal variável, determinante para a classificação ou ocorrência da zona de vida floresta seca/floresta úmida tropical basal - presente somente nestes dois municípios é a biotemperatura, visto que as demais variáveis foram homogêneas e que a área abrangida pelos dois municípios coincide na classe de biotempetura mais elevada na região.

Para Tres (2016), no estudo da classificação climática para o Brasil segundo as zonas de vida de Holdridge, a região em que os municípios estão localizados enquadra-se na classe de biotemperatura $>24{ }^{\circ} \mathrm{C} \leq 27{ }^{\circ} \mathrm{C}$ que, em uma análise de "cluster", demonstra valores altos de biotemperatura, os quais por estarem próximos se agrupam geograficamente, representando uma região que se estende para boa parte do estado de Tocantins, além de estados da região nordeste e norte do Brasil. Para Lopes e Leal (2015), com base nas alterações dos fenômenos climáticos discutidas nos últimos anos, áreas semiáridas teriam tendência a uma acentuação do clima mais seco, reduções da precipitação e, por consequência, elevação da deficiência hídrica, ambos associados com os aumentos da temperatura do ar. Desse modo, a região destes dois municípios favorece o surgimento da zona de vida floresta seca/floresta úmida tropical basal. Porém, ressalta-se que esta zona de vida representa menos de $1 \%$ do território. 
Pode-se constatar que a zona de vida floresta úmida tropical premontana compreende quase a totalidade da área de estudo $(99,4 \%)$. Tal zona de vida, conforme aponta Tres (2016), foi a mais encontrada na região centro-oeste do Brasil, ocupando $62,46 \%$ da superfície, cobrindo praticamente todo o estado de Goiás e o Distrito Federal. Em outros trabalhos, Nogueira et al. (1987) classificaram o estado de Santa Catarina de acordo com o sistema de Holdridge em três zonas de vida: floresta úmida temperada, floresta úmida subtropical e floresta muito úmida temperada,

Comparação entre classificação de Köppen e Holdridge juntamente com uma área de transição da floresta muito úmida temperada para floresta úmida temperada. Milano et al. (1987), ao realizarem a classificação de Holdridge para o estado do Paraná, obtiveram quatro zonas de vida: floresta úmida tropical premontana, floresta úmida subtropical premontana, floresta úmida temperada e floresta muito úmida subtropical basal, além de três áreas de transição entre a floresta úmida temperada e seca temperada, floresta úmida temperada e muito úmida temperada e, por fim, floresta úmida subtropical e muito úmida subtropical.

A Tabela 1 representa a comparação da classificação de Köppen com as zonas de vida de Holdridge.

Tabela 1. Comparação da classificação de Köppen com as zonas de vida de Holdridge em área e porcentagem.

\begin{tabular}{ccccc}
\hline & \multicolumn{3}{c}{ Zonas de vida de Holdridge } \\
\cline { 2 - 5 } $\begin{array}{c}\text { Classificação de } \\
\text { Köppen }\end{array}$ & $\begin{array}{c}\text { Floresta úmida } \\
\text { tropical premontana }\end{array}$ & $\begin{array}{c}\text { Floresta seca/floresta } \\
\text { úmida tropical basal }\end{array}$ \\
\cline { 2 - 5 } & Área $\left(\mathbf{k m}^{2}\right)$ & $\%$ & Área $\left(\mathbf{k m}^{2}\right)$ & $\%$ \\
\hline Aw & $333.073,33$ & 96,88 & $2.075,30$ & 100,00 \\
Am & $10.737,87$ & 3,12 & 0,00 & 0,00 \\
\hline Total & $\mathbf{3 4 3 . 8 1 1 , 2 0}$ & $\mathbf{1 0 0 , 0 0}$ & $\mathbf{2 . 0 7 5 , 3 0}$ & $\mathbf{1 0 0 , 0 0}$ \\
\hline
\end{tabular}

Nota: áreas calculadas com o software ArcGIS.

Fonte: elaborado pelos autores (2018).

Como se pode observar na Tabela 1 , a maior área de correspondência ocorre entre a classificação Aw e a floresta úmida tropical premontana, sendo $333.073,33 \mathrm{~km}^{2}$ equivalentes a $96,88 \%$, enquanto $10.737,87 \mathrm{~km}^{2}$ equivalem a $3,12 \%$ e ocorrem na classificação Am. A zona de vida floresta seca/floresta úmida tropical basal tem $100 \%$ de correspondência com a classificação Aw, perfazendo uma área de $2.075,30 \mathrm{~km}^{2}$.

Assim, o clima Aw juntamente com o relevo plano ou suavemente ondulado da região proporcionam a formação de uma vegetação seca, típica do bioma cerrado, pois o piso altitudinal basal, no qual a área de estudo está inserida, indica que a vegetação ali presente não sofre influência da altitude.
Não existem grandes altitudes na região que sirvam como barreiras naturais às massas de ar atuantes, uma vez que a porção mais baixa está localizada no noroeste goiano, com altitudes mínimas chegando a $186 \mathrm{~m}$, próximas ao curso do Rio Araguaia; e as maiores altitudes podem ser observadas em uma faixa meridional que percorre o nordeste goiano às proximidades da capital federal, sendo que o ponto mais alto atinge 1.670 m e está localizado na Chapada dos Veadeiros, mais precisamente no município de Alto Paraíso (Dias Cardoso et al., 2014). 
Comparação entre a classificação de Holdridge e a vegetação
A comparação entre a classificação de Holdridge e a vegetação apresentou correspondências como pode ser observado abaixo na Tabela 2.

Tabela 2. Comparação entre a classificação em zonas de vida de Holdridge e a vegetação em área e porcentagem.

\begin{tabular}{lcccc}
\hline \multirow{2}{*}{ Tipologia } & \multicolumn{2}{c}{$\begin{array}{c}\text { Floresta úmida } \\
\text { tropical premontana }\end{array}$} & \multicolumn{2}{c}{$\begin{array}{c}\text { Floresta seca/floresta } \\
\text { úmida tropical basal }\end{array}$} \\
\cline { 2 - 5 } & Área $\left(\mathbf{k m}^{2}\right)$ & $\mathbf{\%}$ & Área $\left(\mathbf{k m}^{\mathbf{2}}\right)$ & $\mathbf{\%}$ \\
\hline Savana & $200.398,35$ & 58,29 & $1.774,53$ & 85,51 \\
Savana/floresta estacional & $106.378,33$ & 30,94 & 300,77 & 14,49 \\
Floresta estacional decidual & $20.576,98$ & 5,98 & 0,00 & 0,00 \\
Floresta estacional semidecidual & $16.457,54$ & 4,79 & 0,00 & 0,00 \\
\hline \multicolumn{1}{c}{ Total } & $\mathbf{3 4 3 . 8 1 1 , 2 0}$ & $\mathbf{1 0 0 , 0 0}$ & $\mathbf{2 . 0 7 5 , 3 0}$ & $\mathbf{1 0 0 , 0 0}$ \\
\hline
\end{tabular}

Nota: áreas calculadas com o software ArcGIS.

Fonte: elaborado pelos autores (2018).

Nota-se que a tipologia savana apresentou correspondência de 58,29\% com a zona de vida floresta úmida tropical premontana, enquanto que com a zona de vida floresta seca/floresta úmida tropical basal a correspondência foi de $85,51 \%$. A correlação entre a savana/floresta estacional foi de $30,94 \%$ com a zona de vida floresta úmida tropical premontana e $14,49 \%$ com a zona de vida floresta seca/floresta úmida tropical basal respectivamente.

$\mathrm{Na}$ área de estudo, a vegetação está intimamente ligada aos cursos de água que oferecem a delimitação entre as matas ciliares ou de galeria e as diferentes formações savânicas (Costa et al., 2012).

Além das formações savânicas características do domínio, a fisionomia vegetal incorpora também outros tipos de vegetação com pouca expressividade espacial, mas ecologicamente muito importantes, como as veredas e os palmeirais (Oliveira, 2014).

$\mathrm{Na}$ zona de vida floresta úmida tropical premontana diversas associações vegetais podem ser encontradas, havendo o predomínio das savanas e áreas de transição com a floresta estacional. Atualmente as savanas ocorrem de forma dispersa devido à degradação ambiental pela qual passou e ainda passa o bioma cerrado.

As espécies desse bioma, no decorrer da história evolutiva, foram se adaptando a sazonalidade da região para garantirem a sobrevivência e diversidade, portanto, a fragmentação do cerrado influencia os padrões locais e regionais de biodiversidade devido à perda de micro-hábitats únicos, isolamento do habitat, mudanças nos padrões de dispersão, migração e erosão do solo (Malheiros, 2016).

A floresta estacional decidual apresentou correspondência de 5,98\% com a zona de vida floresta úmida tropical premontana. A floresta estacional decidual ocorre em áreas descontínuas apresentando importantes gêneros madeireiros, tais como: Cedrela (cedro), Jacaranda (jacarandá), Parapiptadenia (angico) (IBGE, 2012).

A floresta estacional semideciual apresentou correspondência de 4,79\% com a zona de vida floresta úmida tropical premontana. $\mathrm{Na}$ zona tropical, tal formação vegetal ocorre associada à região marcada por acentuada seca hibernal e por intensas chuvas de verão (IBGE, 2012). A característica mais marcante do clima de Goiás e do Distrito Federal é a presença de duas estações bem definidas: verão úmido e inverno seco (IMB, 2004), proporcionando o desenvolvimento dessa fisionomia. $\mathrm{Na}$ depressão interiorana do Araguaia, entre 5 e $100 \mathrm{~m}$, chegando em algumas áreas próximo a $200 \mathrm{~m}$ de altitude, ocorre a floresta estacional semidecidual de terras baixas com presença marcante do gênero Cariniana (jequitibá), enquanto que, no planalto central e no contato da floresta ombrófila com a savana, em uma faixa altimétrica que varia de 100 a $600 \mathrm{~m}$ ocorre a floresta estacional semidecidual submontana, evidenciando a ocorrência dos gêneros Hymenaea (jatobá) e Peltophorum (canafístula); em suma, a floresta estacional semidecidual ocorre entremeada a formações savânicas especialmente na região centro-oeste adentrando pelo sul da região através do Rio Paranaíba (IBGE, 2012). 
Tais analogias podem ser correlacionadas com o mapa de vegetação elaborado pelo IBGE (2012), onde as fisionomias dos tipos savana e savana/floresta estacional predominam no local. Como visto, a zona de vida floresta úmida tropical premontana abrange $99,4 \%$ da região, somado ao fato de que a classificação climática de Köppen confere a área de estudo o clima do tipo Aw, exceto para uma pequena porção ao sul a qual apresenta clima do tipo Am, nota-se que a classificação proposta pelo sistema de zonas de vida de Holdridge é satisfatória, uma vez que segue os apontamentos estabelecidos por trabalhos tradicionalmente reconhecidos.

\section{Conclusão}

i. Foram definidas duas zonas de vida para o estado de Goiás e o Distrito Federal com base na classificação de Holdridge.

ii. Verificou-se que em uma mesma zona de vida ocorrem diferentes formações vegetais e que, a savana e a transição savana/floresta estacional prevalecem no território, altamente correlacionadas com a zona de vida floresta úmida tropical premontana, que predomina em $99,4 \%$ da área de estudo. Esta zona de vida apresentou correspondência de 96,88\% com o clima Aw da classificação de Köppen.

iii. A biotemperatura foi a variável que diferiu das demais para os dois municípios localizados no extremo norte do estado e determinou o surgimento da zona de vida floresta seca/floresta úmida tropical basal, que, por sua vez, apresentou $100 \%$ de correlação com o clima Aw, compreendendo $0,6 \%$ do território.

iv. O emprego do sistema de classificação climática de Holdridge foi adequado para classificar o clima de Goiás e do Distrito Federal, pois correspondeu com a classificação de Köppen e com a vegetação.

\section{Agradecimentos}

A presente pesquisa foi realizada com apoio da Coordenação de Aperfeiçoamento de Pessoal de Nível Superior - Brasil (CAPES) Código de Financiamento 001. Agradecemos aos autores Alvares, C. A., Stape, J. L., Sentelhas, P. C., Gonçalves, J. L. M., Sparovek por disponibilizarem a base de dados meteorológicos.

\section{Referências}

Abdala, K. de O., Ribeiro, F. L., 2011. Análise dos impactos da competição pelo uso do solo no estado de Goiás durante o período 2000 a 2009 provenientes da expansão do complexo sucroalcooleiro. Revista Brasileira de Economia 65, 4, 373-400.

Alencar, L. P. de, Mantovani, E. C., Bufon, V. B., Sediyama, G. C., Silva, T. G. F. da. 2014. Variação temporal dos elementos climáticos e da evapotranspiração de referência (ETo) em Catalão, Goiás, no período de 1961 - 2011. Revista Brasileira de Geografia Agrícola e Ambiental 8, 826-832.

Almeida, R. A., Pinto, D. B. F., Primo, D. F., Sena, F. R., Santos, D. M., 2018. Análise espacial e temporal das chuvas médias mensais e anuais na bacia hidrográfica do Rio Mucuri. Revista Engenharia na Agricultura 4, 370-382.

Alvares, C. A., Stape, J. L., Sentelhas, P. C., Gonçalves, J. L. M., Sparovek, G., 2013. Köppen's climate classification map for Brazil. Meteorologische Zeitschrift 6, 711-728.

Alves, E. D. L., 2016. Variabilidade climática no estado de Goiás, Brasil: o caso da precipitação. Geografia em questão, Marechal Cândido Rondon 2, 26-35.

Ayoade, J. O., 2010. Introdução à climatologia para os trópicos. 14. ed. Rio de Janeiro: Bertrand Brasil. 179 p.

Costa, H. C., Marcuzzo, F. F. N., Ferreira, O. M., Andrade, L. R., 2012. Espacialização e sazonalidade da precipitação pluviométrica do estado de Goiás e Distrito Federal. Revista Brasileira de Geografia Física 1, 87-100.

Derguy, M. R., 2017. Clasificación ecológica para la república argentina a partir del modelo de zonas de vida de Holdridge: mapeo, caracterización y tendências de cambio. Cartografías del sur 6, 140-151.

Dias Cardoso, M. R., Marcuzzo, F. F. N., Barros, J. R., 2012. Caracterização da temperatura do ar no estado de Goiás e no Distrito Federal. Revista Brasileira de Climatologia 8, 119-134. ., 2014. Classificação climática de Köppen-Geiger para o estado de Goiás e o Distrito Federal. ACTA Geográfica, Boa Vista, 8, 16, 40-55.

Eloi, C. M. A., 2001. Enquadramento das 'zonas de vida' de Holdridge na classificação climática de Minas Gerais. Tese (Magister Scientiae) Programa de Pós-graduação em Meteorologia Agrícola, Universidade Federal de Viçosa, Viçosa, 71p.

EMBRAPA. Empresa Brasileira de Pesquisa Agropecuária, 2018. Clima. Disponível: <https://www.cnpf.embrapa.br/pesquisa/efb/cli ma.htm>. Acesso: 20 mai. 2018.

GOVERNO DE BRASÍLIA. Geografia. Disponível: <http://www.df.gov.br/333/>. Acesso: 17 nov. 2018. 
Holdridge, L. R., 1967. Life zone ecology. San José: Tropical Science Center, 124 p. ., 2000. Ecologia basada em zonas de vida. San José, Costa Rica: Instituto Interamericano de Cooperación para la Agricultura, $216 \mathrm{p}$.

IBGE. Instituto Brasileiro de Geografia e Estatística, 2012. Departamento de Recursos Naturais e Estudos Ambientais, Manual técnico da vegetação brasileira, 2 ed., Rio de Janeiro, $271 \mathrm{p}$.

2018a. Panorama. Disponível:

<https://cidades.ibge.gov.br/brasil/go/panorama>. Acesso: 26 out. 2018. ., 2018b. Panorama.

Disponível:

<https://cidades.ibge.gov.br/brasil/df/brasilia/pano rama>. Acesso: 18 nov. 2018.

Agricultura, $216 \mathrm{p}$.

IMB. Instituto Mauro Borges de Estatísticas e Estudos Socioeconômicos., 2004. Clima. Disponível em:

<http://www.imb.go.gov.br/pub/GoDados/2004/d ados/01-climate.htm>. Acesso em: 20 maio 2018. 2014. Atlas do estado de

Goiás, Governo de Goiás, Secretaria de Estado de Gestão e Planejamento, Goiânia, 98 p.

Lopes, I., Leal, B. G., 2015. Índice de aridez e tendência a desertificação para estações meteorológicas nos estados da Bahia e Pernambuco 17, 155-172.

Malheiros, R. A., 2016. Influência da sazonalidade na dinâmica da vida no bioma Cerrado. Revista Brasileira de Climatologia 19, 113-128.

Marinho, H. M. A., Cândido, L. M., Cândido, S. de A., Daltro, O., Jaudi, L. M. R., Camargo, E J., Yoshida, P. S., 2016. Análise econômica da evolução do agronegócio em Mato Grosso no período de 1990 a 2010. Revista Faipe 1, 13-24.

Milano, M. S., Brassiolo, M. M., Soares, R. V., 1987. Zoneamento ecológico experimental do estado do Paraná segundo o sistema de zonas da vida de Holdridge. Revista Floresta 17, 1, 6572.

Nascimento, D. T. F., Souza Neto, J. M., Nunes, L. C., 2015. Definição dos anos-padrão para o estudo da pluviometria do estado de Goiás e do Distrito Federal. Brazilian Geographical Journal 1, 272-290.
Nogueira, A. C., Kuniyoshi, Y. S., Soares, R. V., 1987. Zonas de vida para o estado de Santa Catarina segundo a classificação das formações vegetais de Holdridge. Floresta 17, 1/2, 103112.

Oliveira, I. J. de, 2014. Chapadões descerrados: relações entre vegetação, relevo e uso das terras em Goiás. Boletim Goiano de Geografia 34, 2, 311-336.

Penereiro, J. C., Martins, L. L. S., Beretta, V. Z., 2015. Identificação de tendências sazonais dos regimes climático e hidrológico na bacia hidrográfica dos rios Tocantins e Araguaia, Brasil. Revista Geográfica Acadêmica 1, 52-72.

Rigonato, V. D., Almeida, M. G. de., 2003. As fitofisionomias e a interrelação das populações tradicionais com o bioma Cerrado. In: Cultura, conhecimento popular e uso das espécies nativas pelos pequenos agricultores do Cerrado, projeto de pesquisa financiado pelo Programa Centro Oeste de Pesquisa e Pós-Graduação POCPG/CNPq 2001 - 2003. IESA/UFG, Goiânia, 15 p.

Reboita, M. S., Rodrigues, M., Silva, L. F., Alves, M. A., 2015. Aspectos climáticos do estado de Minas Gerais. Revista Brasileira de Climatologia 17, 206-226.

Soares, R. V., Batista, A. C., Tetto, A. F. 2015. Meteorologia e climatologia florestal. Curitiba, $215 \mathrm{p}$.

Tres, A., 2016. Classificação climática para o Brasil segundo as zonas de vida de Holdridge. Dissertação (Mestrado em Engenharia Florestal) -Universidade Federal do Paraná, Curitiba, $\quad 90$ p. $\quad$ Disponível: <https://acervodigital.ufpr.br/bitstream/handle/ 1884/46158/R\%20-\%20D\%20-

$\%$ 20ANDRESSA $\%$ 20TRES.pdf? sequence $=1 \&$ isAllowed=y>. Acesso: 02 mai. 2018.

Toledo, C. E. de. Moraes, E. E., 2018. Levantamento e atualização dos sistemas de irrigação por pivô central instalados nos municípios de Paraúna e Palmeiras de Goiás. Revista Engenharia na Agricultura 26, 277-283.

Torres, F. T. P., Machado, P. J. de O., Introdução à climatologia. 2008. Ubá: Ed. Geographica, Série Textos Básicos de Geografia, 234 p. 